\title{
A rare case of epidermal inclusion cyst: an unusual complication of ear surgery
}

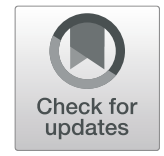

Dilesh A. Mogre", M. D. Fazal Ahmed and T. Parvathi Banu

\begin{abstract}
Background: Epidermal inclusion cysts are common tumours of the hand in industrial workers caused by entrapment of epidermal elements within the dermis. They are unusual in the head and neck region more so in the temporal region.

Case presentation: We present a 27-year-old man with a 3-month history of a slow-growing swelling in the left temporal region. He had a history of chronic otitis media and underwent an end-aural tympanomastoid surgery 5 years earlier. Physical examination revealed a $5 \times 3 \times 2.5 \mathrm{~cm}$ cystic globular minimally tender mass in the temporal fossa along with squamous active otitis media with bony erosion of the outer attic wall. High-resolution computed tomography of the left temporal bone revealed otomastoiditis with erosion of the scutum; ossicles were not identified. We hereby describe the diagnostic challenge and the plan of management of this lesion.

Conclusions: Epidermal inclusion cyst must be considered in the differential diagnosis of temporal fossa lesions especially in patients with a prior history of ipsilateral tympanomastoid surgery.
\end{abstract}

Keywords: Epidermal inclusion cyst, Temporal fossa, Tympanomastoid surgery

\section{Background}

Epidermal inclusion cysts are an extremely rare clinical entity in the head and neck region. These are ectodermal in origin cysts located within subcutaneous tissue, associated with penetrating trauma or surgery. These lesions are often seen with multiple minor occupational traumas in farmers, carpenters and tailors [1]. The implantation of epidermal elements from otological procedures is extremely rare, and very few cases have been reported till date; hence, we present this rare case. "Everything must be taken into account. When the fact does not meet the theory let go the theory." [2].

Otitis media is a very common condition seen in developing countries rarely resulting in complications. The differential diagnosis of temporal fossa swelling are usually infective such as lymphadenitis and suppuration mainly otogenic or dental and traumatic aetiology. Soft-

\footnotetext{
* Correspondence: damogre@gmail.com

Department of ENT and Head Neck Surgery, Centenary Hospital, WT Patil

Marg, Govandi, Mumbai, Maharashtra 400088, India
}

tissue lesions are quite rare in this anatomical region, hence presenting a diagnostic challenge especially with a history of otorrhoea and previous ear surgery. Our case is amongst the few cases reported globally of a large epidermoid cyst within the temporal fossa following endaural ear surgery. The relative scarcity of case reports thus emphasises the rarity of this clinical condition.

Otological procedures require various skin incisions as an approach to the middle ear such as Wildey's postaural incision, Rosen's endomeatal incision and Lempert's endaural incision. As with any surgical intervention, these incisions present with the theoretical risk of implantation of skin or ectodermal elements in the subcutaneous tissue; whilst it holds true for all surgical incisions, the endaural incision carries the highest risk for implantation [3]. This risk of implantation of squamous epithelium increases with the surgery for cholesteatoma. There is evidence on the development of epidermal cysts in the middle ear or tympanic membrane presenting as keratin pearls or secondary cholesteatoma; however, literature search reveals sparse reports of epidermal inclusion cysts within the

\section{Springer Open}

(c) The Author(s). 2020 Open Access This article is licensed under a Creative Commons Attribution 4.0 International License, which permits use, sharing, adaptation, distribution and reproduction in any medium or format, as long as you give appropriate credit to the original author(s) and the source, provide a link to the Creative Commons licence, and indicate if changes were made. The images or other third party material in this article are included in the article's Creative Commons licence, unless indicated otherwise in a credit line to the material. If material is not included in the article's Creative Commons licence and your intended use is not permitted by statutory regulation or exceeds the permitted use, you will need to obtain permission directly from the copyright holder. To view a copy of this licence, visit http://creativecommons.org/licenses/by/4.0/. 

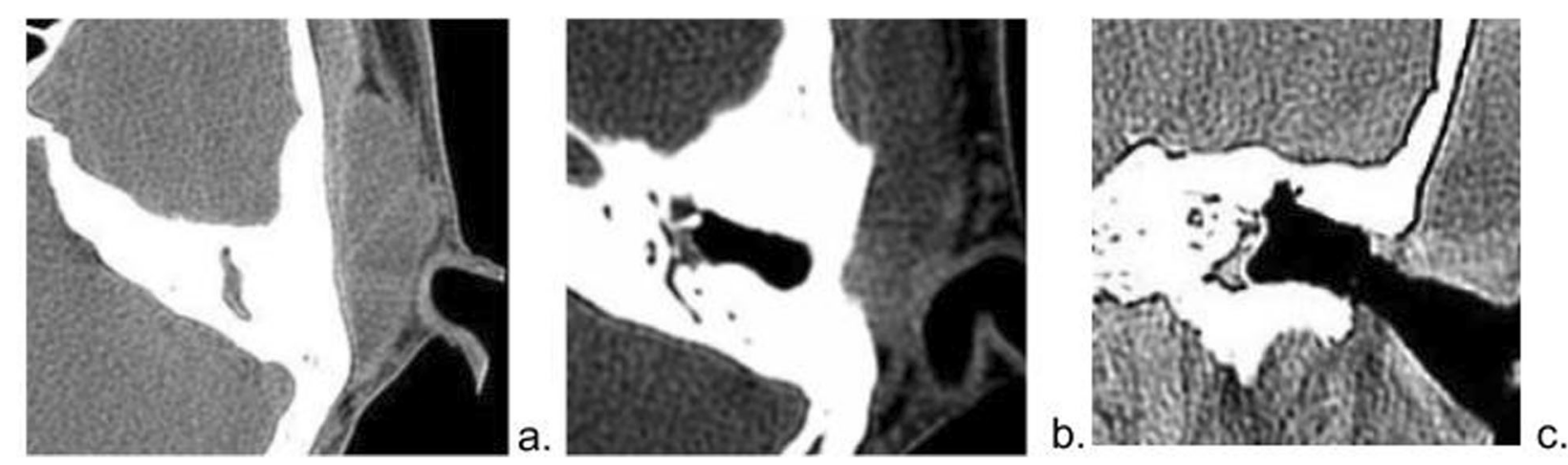

Fig 1 Computed tomography of the left temporal bone showing a non-enhancing cystic lesion in the left temporal fossa. a, b Axial view and scutum and ossicular erosion. c Coronal view

subcutaneous tissue after ear surgery. Overall, there are three sites of preponderance for development of such cysts: the temporal fossa, the parotid region and deeper cysts extending into infratemporal fossa or the parapharyngeal region. Tovi et al. reported two cases of epidermal cysts after otological procedure within the temporal fossa which had an extension into the infratemporal fossa [4]. A novel endoscopic approach was reported by Fontenot et al. for the excision of an epidermoid cyst within the temporal fossa after tympanoplasty [5]. Ulku et al. reported multiple separate masses resulting from epidermal cysts in the temporal and parotid region with peristyloid extension on MRI in a 46-year-old man with history of modified radical mastoidectomy [6]. Such epidermoid cysts have also been reported by Thompson and Bradley, Walshe et al., and Ozcan et al. within the parotid region following ear surgery [7-9].

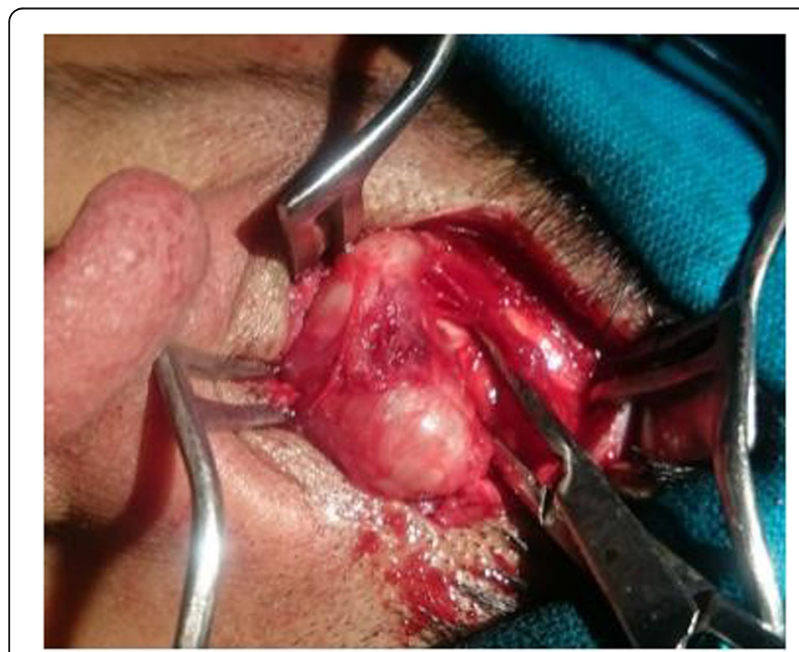

Fig. 2 Intraoperative photograph showing the epidermal inclusion cyst in the temporal fossa deep to the anterior fibres of the temporalis muscle

\section{Case presentation}

A 27-year-old male presented with a painless swelling in the left temporal region along with ear discharge from 3 months. He had a history of left ear tympanomastoid surgery via endaural incision 5 years back for chronic otitis media; there is no history of intraoperative or immediate postoperative complication. On otomicroscopy, severe retraction of pars flaccida with keratin debris with erosion of ossicles and scutum was revealed. On external examination, a small well-healed endaural scar was seen along with a fluctuant minimally tender swelling in the temporal fossa extending from the preaural area to the retroauricular groove along the superior aspect of the pinna measuring $5 \times 3 \times 2.5 \mathrm{~cm}$ pushing the pinna forward and outward with no signs of acute infection. A high-resolution computed tomography of the left temporal bone revealed otomastoiditis with erosion of the scutum (Fig. 1). There is a large cystic lesion in close

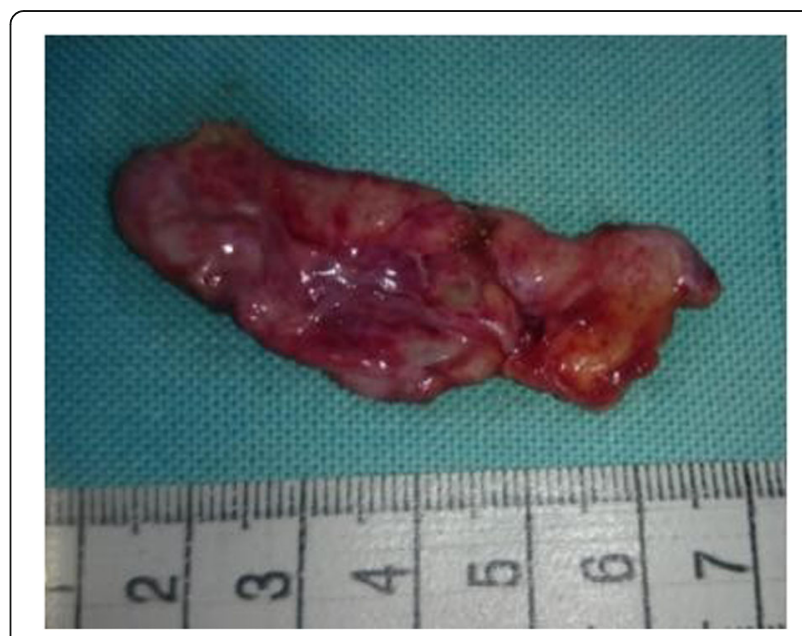

Fig. 3 Postoperative picture of epidermal inclusion cyst excised in toto 
relation to the temporal bone located in the temporal fossa deep to the temporalis muscle which was displacing the pinna laterally.

Cytology of the aspirated contents showed numerous keratin lamellae without inflammatory infiltrate. The patient underwent staged treatment; firstly, the epidermal inclusion cyst was excised from a small superiorly based postaural incision. This dermoid was deep to the temporalis muscle, and the fascia over the muscle was deficient in the preaural region as a result of temporalis fascia graft for previous otological procedure. The cyst was dissected, and the fibrous septae adherent to the soft tissue of the incisural scar tissue were divided and excised in toto (Figs. 2 and 3). There was no extension of epithelium into the middle ear or attic. The scutum erosion was smooth with no ragged edges indicating drilling during previous ear surgery; however, no detailed notes could be obtained. The postoperative healing was unremarkable. Histopathology confirmed the findings of cytology as an epidermoid inclusion cyst. We cannot comment on the source of the original epithelium due to lack of adequate surgical details of the previous ear surgery. Intraoperatively, there was dense adhesion between the endaural scar and the cyst with no direct communication between the cyst and the attic or mesotympanum, thus ruling out direct extension of cholesteatoma. However, implantation of the squamous epithelium from cholesteatoma during previous tympanomastoid surgery cannot be ruled out. Thus, in our case, the origin of the epithelium can be the implantation of squamous epithelium via endaural incision or implantation of cholesteatoma during previous ear surgery.

Later, the patient underwent a revision tympanomastoidectomy for the treatment of chronic otitis media squamous active type. The patient has been in constant follow-up and is currently asymptomatic.

\section{Conclusions}

In summary, the literature search highlights the fact that in cases with previous middle ear surgery, there is a risk of implantation of squamous epithelium; hence, epidermal inclusion cyst must be considered in the differential diagnosis of temporal fossa lesions especially in patients with a prior history of ipsilateral tympanomastoid surgery. The authors recommend complete excision of these cysts without spilling the contents to prevent recurrence.

\section{Acknowledgements}

Not applicable

Authors' contributions

DM: concept, literature search, major contributor in writing manuscript; PB, FA: literature search, manuscript editing; FA: proofreading. All authors read and approved the final manuscript.
Funding

None

\section{Availability of data and materials \\ Not applicable}

Ethics approval and consent to participate

Centenary Hospital Institutional Ethical Committee permission was obtained, and written informed consent was obtained from the patient.

\section{Consent for publication}

Written consent was obtained from the patient including the consent to publish clinical images without revealing identity.

Competing interests

The authors declare that they have no competing interests.

Received: 19 March 2020 Accepted: 14 April 2020

Published online: 04 June 2020

References

1. Saraf S (2012) Implantation dermoid of the palm: an unusual presentation. Indian Dermatol Online J 3(1):37

2. Christie A (1920) The mysterious affair at Styles: a detective story. Grosset \& Dunlap, New York

3. Kothandaraman S, Thiagarajan B (2013) A cheesy affair!--report Of A Case Of An Epidermoid Cyst Of Parotid. Online J Otolaryngol 3(3)

4. Tovi F, Bartal N, Zirkin C (1985) Epidermal cysts of temporal fossa: an unusual complication of ear surgery. Ann Otol Rhinol Laryngol 94(2):162164

5. Fontenot MR, Tolisano AM, Kutz JW Jr (2019) Endoscopic removal of an epithelial cyst of the zygoma. J Craniofac Surg 30(1):e8-e9

6. Ulku CH, Uyar Y, Kocaogullar Y, Avunduk MC (2004) latrogenic epidermal inclusion cyst of the parapharyngeal space: unusual complication of ear surgery. Skull Base 14(01):47-51

7. Thompson AC, Bradley PJ (1991) latrogenic epidermoid cyst of the parotid region following ear surgery. J Laryngol Otol 105(3):227-228

8. Walshe P, Low C, Lucey D, Hone S, O'Dwyer T (2005) Parotid masses in patients with previous ear surgery. Ir Med J 98(4):110-111

9. Ozcan KM, Dere H, Ozcan I, Gun T, Unal T (2006) An epidermal cyst in the parotid gland following ear surgery: a case report. B-ENT 2(4):193-195

\section{Publisher's Note}

Springer Nature remains neutral with regard to jurisdictional claims in published maps and institutional affiliations.

\section{Submit your manuscript to a SpringerOpen ${ }^{\bullet}$ journal and benefit from:}

- Convenient online submission

- Rigorous peer review

- Open access: articles freely available online

High visibility within the field

- Retaining the copyright to your article

Submit your next manuscript at $>$ springeropen.com 